\title{
Switching Inhalers: A Practical Approach to Keep on UR RADAR
}

\author{
Alan Kaplan · Job F. M. van Boven
}

Received: July 29, 2020 / Accepted: September 23, 2020 / Published online: October 13, 2020

(C) The Author(s) 2020

\section{ABSTRACT}

The choice of an inhaler device is often as important as the medication put in it to achieve optimal outcomes for our patients with asthma and/or COPD. With a multitude of drug-device combinations available, optimization of respiratory treatment could well be established by switching devices rather than changing or even augmenting pharmacological or non-pharmacological therapies. Importantly, while notable between-device differences in release

\section{A. Kaplan $(\bowtie)$}

Department of Family and Community Medicine, University of Toronto, Toronto, Canada

e-mail: for4kids@gmail.com

\section{A. Kaplan}

Primary Care Respiratory Research, Observational and Pragmatic Research Institute, Singapore,

Singapore

\section{A. Kaplan}

Family Physician Airways Group of Canada,

Toronto, Canada

\section{J. F. M. van Boven}

Department of Clinical Pharmacy and Pharmacology, Groningen Research Institute for Asthma and COPD (GRIAC), University Medical Center Groningen, University of Groningen, Groningen, The Netherlands

\section{J. F. M. van Boven}

Medication Adherence Expertise Center of the Northern Netherlands (MAECON), Groningen, The Netherlands mechanism, particle size, drug deposition and required inspiratory flow exist, a patient uncomfortable with their device is unlikely to use it regularly and certainly will not use it properly. Switching requires a careful process and should not be done without patient consent. Switching devices entails several steps that need to be considered, which can be guided using the UR-RADAR mnemonic. It starts with (i) UncontRolled asthma/COPD (or UnaffoRdable device), followed by RADAR: (ii) review the patient's condition (e.g. diagnosis, phenotype, co-morbidities) and address reasons for suboptimal control (e.g. triggers, smoking, non-adherence, poor inhaler technique) to be ruled out before switching; (iii) assess patient's skills related to inhalation (e.g. inspiratory force); (iv) discuss inhaler switch options, patient preferences (e.g. size, daily regimen) and treatment goals; (v) allow patients input and use shared decision-making to decide final treatment choice, acknowledging individual patient skills, preferences and goals; and (vi) re-educate to the new device (at minimum, physical demonstration, verbal explanation and patient repetition, both verbally and physically) and prime the patient for the follow-up (i.e. explain the future patient journey, including multidisciplinary work flows with physicians, nurses and pharmacists). 
Keywords: Adherence; Asthma; Brand; Change; COPD; Cost-effectiveness; Device; Generic; Inhaler; Switch

\section{Key Summary Points}

Switching requires a careful process and should not be done without patient consent. Switching devices in daily clinical practice can be guided using the UR-RADAR mnemonic.

(i) UncontRolled asthma/COPD (or: UnaffoRdable device), followed by:

(ii) Reassess the patient's condition (e.g. diagnosis, phenotype, co-morbidities) and address reasons for suboptimal control (e.g. triggers, smoking, non-adherence, poor inhaler technique) to be ruled out before switching.

(iii) Assess patient's skills related to inhalation (e.g. inspiratory force).

(iv) Discuss inhaler switch options, patient preferences (e.g. size, daily regimen) and treatment goals.

(v) Allow patients input and use shared decision-making to reach a final treatment choice taking into account individual patient skills, preferences and goals.

(vi) Re-educate to the new device (at minimum, physical demonstration, verbal explanation and patient repetition, both verbally and physically).

\section{DIGITAL FEATURES}

This article is published with digital features, including a summary slide, to facilitate understanding of the article. To view digital features for this article go to https://doi.org/10.6084/ m9.figshare.12993395.

\section{INTRODUCTION}

Asthma and chronic obstructive pulmonary disease (COPD) are common illnesses with a significant global burden [1]. COPD is currently the fourth leading cause of death worldwide, and the World Health Organization (WHO) predicts that it will become the third leading cause by $2030[2,3]$. Both asthma and COPD can also have a major socioeconomic impact, e.g. due to loss of productivity [4]. Despite effective non-pharmacologic and pharmacologic treatments being available and widely recommended in national and international guidelines, a large share of patients with asthma and COPD remain uncontrolled $[5,6]$.

One of the important reasons for suboptimal disease control relates to poor adherence to pharmacological treatment. The reasons behind non-adherence can be related to patient, health system or medication factors. In asthma and COPD treatment, most of the medication is accessed by the inhalation route, and therefore the issue of proper and consistent inhaler usage will have significant effect on patient outcomes. Amongst other factors, inhaler usage can be influenced by patient knowledge, education, inhaler device convenience and satisfaction, age, adverse effects and medication costs $[7,8]$. As such, an optimal match between the patient and his or her inhaler can make a critical difference regarding clinical outcomes.

In recent years, a plethora of novel inhaler devices have become available, allowing more options in the type of inhaler to be prescribed. Notably, this could make one consider trying a different inhaler in the case of suboptimal clinical response, but also insurer or cost-driven switches may become more prevalent. Switching could involve brand-brand, brand-generic, generic-brand or generic-generic switches. Exact switching rates differ per type of drug, disease, country and health plan. For example, in the Netherlands, a monthly median of $7 \%$ of salbutamol users switched between inhalers during the period 2009-2016 [9], while in the United Kingdom, inhaler switching rates were between 2 and $6 \%$ for asthma and COPD, respectively, over the period 2000-2016 [10]. Of 
note, contrasting with oral therapies such as tablets or capsules, most of the inhaler switches involve a completely different device with its own characteristics, administration and handling technique. Therefore, the process of switching inhalers requires a careful approach. This article will look at the reasons for changing inhalers, the steps involved, and the benefits and costs of making those changes.

This article is based on previously conducted studies and does not contain any studies with human participants or animals performed by any of the authors.

\section{WHEN TO SWITCH TO A DIFFERENT INHALER?}

When a patient is suffering from uncontrolled asthma or COPD, multiple underlying issues may give rise to the decision to switch inhalers. These include adherence issues, poor inhaler technique, patients' health, adverse events, patient preferences and cost considerations, and are further discussed below.

\section{Adherence Issues}

Inhaler therapy is the cornerstone of treatment for asthma and COPD, with pressurized metered-dose inhalers (pMDI) and dry powder inhalers (DPI) the two most frequently used inhalation devices [11]. Importantly, in order to achieve optimal benefit from their inhaled drug, patients need to take their maintenance inhaler persistently, take medication in the doses and at the times instructed, and use their inhaler properly to ensure that the drug is correctly delivered to the site of action [12]. Numerous drug-inhaler combinations have been created to facilitate effective care [13]. However, despite the efficacy of inhaled asthma medications, it is estimated that $50-84.6 \%$ of adults and children on long-term therapy for asthma fail to adhere to their treatment regimen [14-16]. There are several strategies to enhance medication adherence in patients with asthma and COPD, including the use of dose counters, reminders, education and motivational interviewing $[17,18]$. Still, these strategies may not be sufficient, and some patients remain uncontrolled. Taking into consideration that misunderstanding about inhaler regimen or use could be reasons for lack of adherence [8], one other solution is to change the inhaler to a device the patient is more comfortable with or has a higher preference for. Of note, involving the patient in the treatment selection, i.e. by use of 'shared decision-making', has been shown to benefit asthma outcomes [19]. A recent UK study indicated that not only may switching inhalers enhance adherence, but it also did not affect safety and could even save considerable costs [10]. In summary, an inhaler switch may be indicated in the case of patients with uncontrolled asthma/COPD and persistent non-adherence despite interventions.

\section{Poor Inhaler Technique}

Even while inhaler design has evolved over the past few decades, inhalation errors remain common, with the accompanying lack of efficacy, causing patient frustration [20]. Indeed, incorrect inhaler technique is common across devices, with up to $100 \%$ of patients demonstrating at least one error [21]. Devices differ in their ability to be used based on the way they are actuated. The drug dose of pMDIs and soft mist inhalers (SMIs) is released by hand pressing a button on the inhaler. As such, the patient needs good hand-mouth coordination and needs to carefully time the moment when they start inhaling. The drug dose of DPIs is released by a mechanical force produced by the patient's inhalation manoeuvre. As such, no coordination is needed. Additionally, the inhalation technique is vastly different, with the basic tenet being that dry powders require more forceful inhalation, while pMDIs must be inhaled very slowly. SMIs are somewhat more forgiving. The pMDI or SMI can be used with a chamber, which makes the technique easier and can increase drug deposition in the lungs, but increases cost and decreases portability [22]. An issue that can further complicate inhaler technique errors is the prescribing of multiple 
different inhalers to the same patient. Using different inhaler types can cause confusion and decrease efficacy [23]. Evidence in COPD patients who were prescribed one or more additional inhaler devices requiring similar inhalation techniques as their previous device(s) showed better outcomes than those who were prescribed devices requiring different techniques [24]. Multiple inhalers in asthma have also been shown to cause confusion [25].

In summary, in this group of patients with poor inhaler technique, changing the inhaler type, dose and frequency to a device the patient is comfortable with can help to resolve this issue. If multiple inhalers are prescribed, aim for uniformity in inhaler type. Keep in mind that even the new inhaler devices may still not be completely intuitive for the patient. Therefore, inhaler training and frequent checking and reinforcement remains necessary [26]. Also, healthcare providers should make sure they are capable of providing this training as even for professionals this can be challenging [27].

\section{Physical Limitations}

Specific physical patient features may also be a reason to switch inhalers. For example, peak inspiratory flow limitations in COPD may lead to suboptimal drug deposition for some DPIs in certain patients [28]. Again, lack of deposition will lead to poorer outcomes including rehospitalizations, exacerbations and worsening symptoms [29, 30]. Factors that can predict suboptimal flow rates in patients with COPD can be found in a 'PIF assessment tool' [31] created for such (Fig. 1), and include patient's age [29], lung severity [32], degree of hyperinflation, respiratory muscle strength limitations [33], gender [34] and recent exacerbation [35]. This seems not to be a problem in asthma, however.

Non-pulmonary physical limitations may also make the use of some devices difficult. Examples of this include hand arthritis, both osteo- and rheumatoid, and loading and dispensing drug from the Respimat, Turbuhaler and even pMDIs [36], or dealing with loading capsules such as with the HandiHaler or
Breezhaler. Additionally, cognitive issues may necessitate the medication being delivered to the patient, not by the patient [37]. In these patients, the use of a pMDI with a valved holding chamber (VHC) or spacer or the use of a nebulizer is required to facilitate proper inhalation.

\section{Side Effects}

Local or systemic adverse effects may also drive the choice to switch inhalers. Using a pMDI with a spacer or valved holding chamber, or changing to inhaled corticosteroids (ICS) that require esterification for effect, can decrease the risk of monilial infections or voice changes [38]. Some patients find dry powder irritating to the throat, while others find the 'Freon' effect of pMDIs discomforting, which was a larger problem in the old CFC (chlorofluorocarbons) than in the current HFA (hydrofluoroalkane). The particle size expelled from the device will have implications for drug delivery, with smaller particles reaching the lung periphery more effectively. Being that most of the lung is small airways, it is felt that some drugs, like ICS, may have increased efficacy if reaching smaller airways [39]. Smaller particles may have less upper airway deposition, could be administered at lower dose and may therefore reduce adverse events and costs [40]. In addition, drugs that are prodrugs, being metabolized in the lung to the active drug, tend to also have fewer upper airway side effects [41].

\section{Patient Preferences}

Patients may intrinsically prefer one device over another simply for reasons of color, size and shape. Patient preference factors also include ease of handling, choice of a once vs twice daily regimen, a short inhalation time, fast onset of action and low inhalation resistance [42]. The use of motivational interviewing techniques to learn what device the patient actually wants to use can help guide choices. A shared-care approach between the clinician and patient to ensure preferences and goals are reviewed with comprehensive patient education, including 

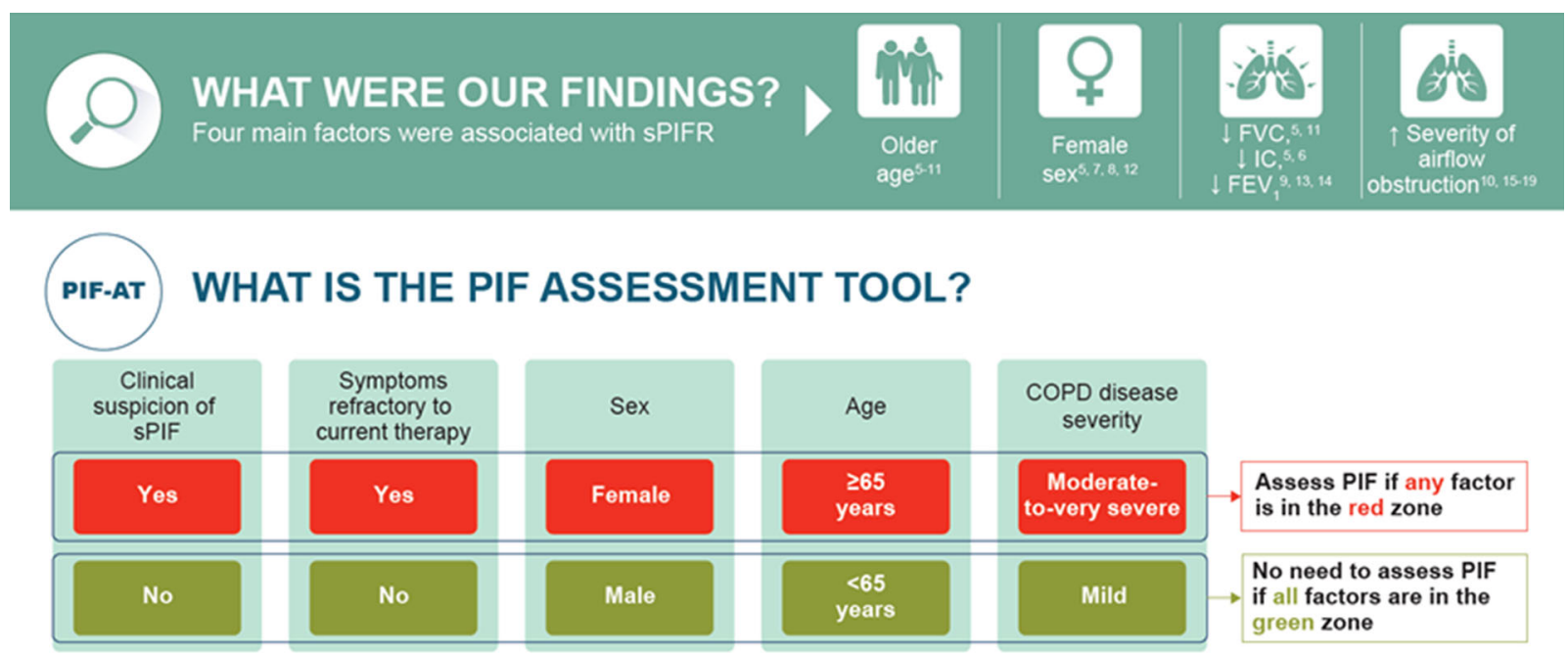

L PIF is an important patient-related factor influencing inhaler choice

L A DPI should be prescribed only after ensuring sufficient PIFR for the inhaler being considered

L Metered-dose inhalers + spacers, slow-mist inhalers, and nebulizers require a lower PIFR and can be considered for patients with SPIFR

L PIF-AT could help identify patients at risk of sPIF but requires further evaluation and validation

Fig. 1 Peak inspiratory flow (PIF) assessment tool: a simple tool for assessing the risk of suboptimal PIF (sPIF) in chronic obstructive pulmonary disease (COPD) (AAFP [31])

device training, can also improve outcomes [19]. As most prescriptions begin in primary care, the primary care physician has a vital role in optimizing outcomes for patients with asthma or COPD by selecting inhaler devices that are effective and preferred by the individual patient [22]. Patient preference may be a reason to alter initial inhaler choice. Notably, while it is important to involve patient preferences in initial inhaler choice, this factor is at least equally important in the decision to switch inhalers. In qualitative research, patients indicated that non-consented inhaler switches resulted in a worse relationship with their doctor, less confidence in their medication and worse disease control perception [43]. Changing the device, but continuing the same medication at equivalent dosing, does not reduce drug efficacy [44].

\section{Cost Considerations}

With considerable cost differences between inhalers in the same drug class, financial considerations may be another justifiable reason to switch inhalers. Cost is a limitation for many patients in many parts of the world and will often also limit formulary inclusions [45]. Switching inhalers due to cost may be necessary to ensure continued use with good adherence. A patient that cannot bear the co-payments may stop or skip treatment.

While concerns abound about switching for cost reasons alone leading to poorer outcomes, real-world evidence is to the contrary in the United States [46], the United Kingdom [10] and Korea [47]. Even switching from one type of inhaler to another, such as from a DPI to a pMDI delivering an ICS/long-acting beta agonist (LABA) for asthma, has been shown to be successful as far as continued efficacy in most patients [48], with favourable cost implications $[10,47]$. Similarly, switching between DPIs did not show efficacy issues and was acceptable to clinicians and patients [49].

That being said, despite the financial incentives, often due to formulary choices, the arbitrary changing of inhalers should not be taken lightly. Education and time has been taken to ensure adequate inhaler technique and personalized care decisions are often involved. If reeducation on the new device takes more time and requires multiple extra consultations, the 
cost reductions due to a cheaper inhaler may be completely offset [50]. Moreover, a change undertaken without careful consideration, or without patient consent, could disrupt the current management strategy and destabilize the patient-doctor relationship or even outcomes [43]. This is particularly a concern in changing to a different type of device, e.g. DPI to pMDI, as the inhalation technique is different. In addition, with some medications having characteristics such as particle size, differences in metabolism and differences in drug distribution, there can be untoward deterioration in efficacy or increased risk of adverse effects.

\section{WHAT INHALER SHOULD I RECOMMEND TO MY PATIENT?}

Given the abovementioned issues, which inhaler should be chosen? Basically, this decision should be based on a balanced mix of inhaler characteristics, the intended molecule to be prescribed, disease characteristics and patient preferences. Finally, a personalized discussion and individual choice should be made for each patient, taking into account the pros and cons of each inhaler. See Table 1 for an overview of the advantages and disadvantages of each inhaler type, which could be considered and used to make your final decision, together with the patient. Choices regarding device can involve, amongst others, required actuation/coordination, portability, type of propellant, dosing schedule, availability of a dose counter, patients' inspiratory flow, device maintenance, uniformity of device between reliever and controllers, need for device priming and the need for loading a capsule (i.e. multidose vs single dose).

\section{HOW TO MAKE THE SWITCH TO A DIFFERENT INHALER FOR YOUR PATIENT?}

For many patients, switching inhalers may be a beneficial or cost-effective treatment option. However, switching devices in daily clinical practice involves a careful process and entails several steps that need to be considered, for which the UR-RADAR mnemonic may be a practical approach (Fig. 2).

(i) UncontRolled asthma or COPD? (or UnafforRdability)

At first, from a clinical point of view, the starting point for switching inhalers should be uncontrolled asthma or COPD. Alternatively, from an economic point of view, it could be unaffordability of the current device.

(ii) Review patient's condition and address reasons for suboptimal control

The authors believe that basics should be valued first. In this review, you could think of the diagnosis (is it really asthma or COPD?), the phenotype, triggers (e.g. pollution, dust), smoking, poor adherence, poor inhaler technique or relevant comorbidities (e.g. allergies, depression) that impact control.

(iii) Assess patient's skills related to inhalation Here, you could check the patient's hand-mouth coordination and inspiratory force (e.g. to be checked with an InCheck DIAL device).

(iv) Discuss inhaler switch options, preferences and treatment goals

Are you changing drug within or outside pharmacologic class, changing from a single therapy to a dual or even triple therapy? Does the patient prefer once or twice daily administration? Does the patient prefers a certain size of inhaler? Do you want a product with an electronic adherence capability?

(v) Allow patients input in making final switching decision

Decide together with the patient on your final device switch, taking into account preferences, perceptions and beliefs regarding therapy.

(vi) Re-educate to the new device and highlight the importance of follow-up

When you change, you need to go back to the beginning with reviewing how the drug is to be taken, why the drug is being used and how it is different from the previous method. Then, training on technique until proficiency is 
Table 1 Considerations when choosing an inhaler device, reproduced with permission from [22]

\begin{tabular}{|c|c|c|}
\hline Inhaler & Advantages & Disadvantages \\
\hline \multirow[t]{5}{*}{ pMDI } & Portable and compact & Requires coordination \\
\hline & Multi-dose device & High deposition in mouth and oropharynx \\
\hline & Metered-dose & 'Cold Freon' effect \\
\hline & Established/familiar & Contains propellants \\
\hline & Available for most inhaled medications & \\
\hline \multirow[t]{5}{*}{ pMDI + spacer } & Lower dependency on inspiratory effort & Less portable than pMDI \\
\hline & Easier to coordinate & Certain spacers may acquire electrostatic \\
\hline & Higher lung deposition than pMDI & charge \\
\hline & Reduced mouth and oropharynx deposition & Additional cost to pMDI \\
\hline & & Requires regular maintenance \\
\hline \multirow[t]{3}{*}{ BA-MDI } & Portable and compact & Contains propellants \\
\hline & Multi-dose device & 'Cold Freon' effect \\
\hline & Breath-actuated & Requires a moderate inspiratory effort \\
\hline \multirow[t]{5}{*}{ DPI } & Portable and compact & Requires a minimum inspiratory effort \\
\hline & Breath-actuated & May not be appropriate for emergency \\
\hline & Does not contain propellants & situations \\
\hline & Multi-dose devices available & $\begin{array}{l}\text { Multiple designs (may be confusing for the } \\
\text { patient) }\end{array}$ \\
\hline & & May be complicated to load \\
\hline \multirow[t]{6}{*}{ SMI } & Portable and compact & Not breath-actuated \\
\hline & Multi-dose device & Only one device currently available \\
\hline & Lower dependency on inspiratory effort & \\
\hline & High fine-particle fraction & \\
\hline & $\begin{array}{l}\text { High lung deposition; low mouth and oropharynx } \\
\text { deposition }\end{array}$ & \\
\hline & Does not contain propellants & \\
\hline \multirow[t]{5}{*}{ Nebulizers } & Can be used at any age & Most lack portability \\
\hline & Can be used by acutely ill & Some require an outside energy source \\
\hline & No specific inhalation technique required & Noisy \\
\hline & Can be used to dispense drugs not available as pMDI or & Can result in longer treatment times \\
\hline & DPI & Can be expensive \\
\hline
\end{tabular}

$B A-M D I$ breath-actuated metered-dose inhaler, $D P I$ dry powder inhaler, $p M D I$ pressurized metered-dose inhaler, $S M I$ soft mist inhaler 


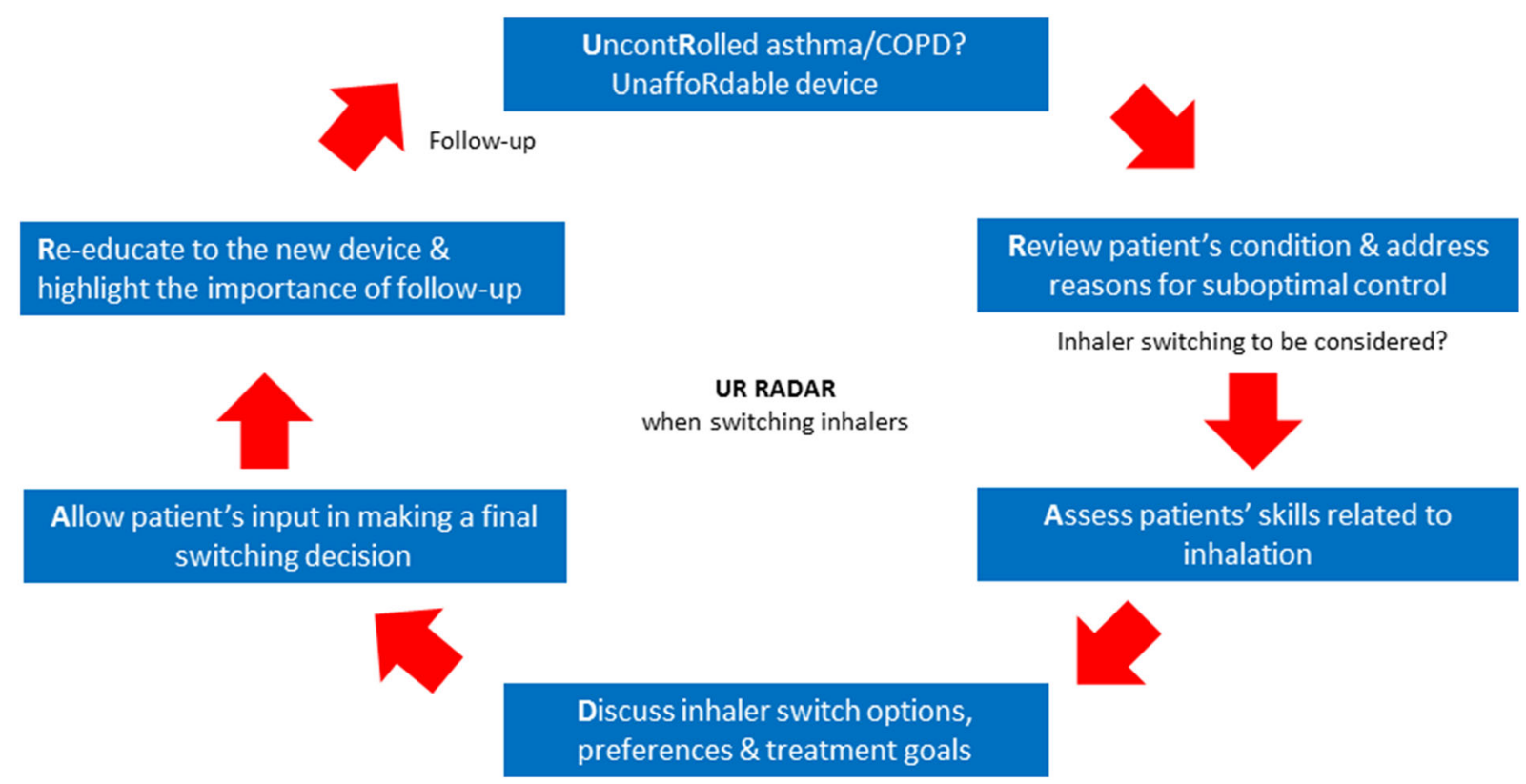

Fig. 2 Using UR RADAR when considering a switch of inhalers

established is important. Ideally, good inhaler training includes a physical demonstration, verbal explanation and patient repetition, both verbally and physically. Notably, the teach-back method is a reliably efficient one, wherein after explanation and practice, the patient 'teaches back' how to use the inhaler properly [51, 52]. The Global Initiative for Asthma (GINA) [53] advocates the $4 C^{\prime}$ 's in inhaler device management for your patient:

- Choose: choose the most appropriate inhaler device for the patient before prescribing.

- Check: check inhaler device technique at every opportunity, including asking the patient to demonstrate their inhaler.

- Correct: show the patient how to use the device correctly via a physical demonstration and recheck technique frequently.

- Confirm: clinicians should be able to demonstrate correct inhaler technique. Skills training can be reinforced by pharmacists and nurses.

When a change is made, reinforcement of the device technique outside the office can be done with provision of written information and/or regionally or nationally uniform recommendations of professional (online) videos showing device technique [54]. Clearly, followup to ensure that goals are met is important. It is important to explain and prime the patient for their future journey and provide the patient with a self-management plan if preferred. In particular, each exacerbation requires a review of the medication regimen, including inhaler technique. Regarding the optimal length of follow-up, this depends on the type of medication being used. Bronchodilator efficacy or deterioration should take place within a couple of weeks. ICS take longer to work, and a review within 3 months would be appropriate. Review can include symptoms as measured by validated questionnaires, but could also include lung function measurement to ensure optimization of care. When working in multidisciplinary teams, coordinate the follow-up care with all disciplines involved, including the roles of physicians, educators, nurses and pharmacists.

\section{CASE EXAMPLES}

1) Asthmatic patient currently uncontrolled on a DPI ICS/LABA for maintenance treatment and a pMDI short-acting beta agonist (SABA) for reliever therapy. With the DPI requiring rapid, forceful inhalation and the 
pMDI requiring slow, less forceful inhalation, this is a set-up for errors. It would likely be best to convert both reliever and controller to the same type of inhaler. With the new GINA recommendations [53], consideration of an ICS/formoterol reliever of the same type could be given with the same ICS/formoterol controller to allow consistency in drug delivery and also potentially improve outcomes.

2) COPD patient without improvement in breathlessness on DPI LABA/LAMA. Adherence, technique, diagnosis and comorbidities have been reviewed, but his peak inspiratory flow rate (PIFR) is $<30$ as checked with the In-Check DIAL device [55]. Switching to a pMDI ( \pm valved holding chamber), SMI or nebulizer can overcome this limitation in a patient with suboptimal PIFR.

\section{CONCLUSIONS}

The best outcomes for patients with asthma and COPD are facilitated by the medication: (1) reaching the lung effectively, requiring good adherence, and (2) appropriately, necessitating appropriate device use. With the introduction of many new types of devices comes therapeutic confusion, but also opportunity to tailor the product to the individual patient to improve outcome. Poor adherence, poor technique, physical limitations, side effects, patients preferences and costs may all be valid reasons to switch inhaler device. Switching inhalers can have beneficial clinical and economic consequences. Yet, it is important to recognize that this change requires a careful process including patient consent, clinical assessment, patient discussion, device re-training and follow-up.

\section{ACKNOWLEDGEMENTS}

Funding. No funding or sponsorship was received for this study or publication of this article.
Authorship. All named authors meet the International Committee of Medical Journal Editors (ICMJE) criteria for authorship for this article, take responsibility for the integrity of the work as a whole, and have given their approval for this version to be published.

Disclosures. Alan Kaplan has received support as a speaker or Advisory Board member for AstraZeneca, Behring, Boehringer Ingelheim, Covis, Griffols, GSK, Novo Nordisk, Pfizer, Sanofi, Teva and Trudell Medical. Job van Boven has received consultancy fees, honorarium and research funding from AstraZeneca, Boehringer Ingelheim, Chiesi, Menarini, Novartis, Teva and Trudell Medical to consult, give lectures, provide advice and conduct independent research, all paid to his institution.

Compliance with Ethics Guidelines. This article is based on previously conducted studies and does not contain any studies with human participants or animals performed by any of the authors.

Open Access. This article is licensed under a Creative Commons Attribution-NonCommercial 4.0 International License, which permits any non-commercial use, sharing, adaptation, distribution and reproduction in any medium or format, as long as you give appropriate credit to the original author(s) and the source, provide a link to the Creative Commons licence, and indicate if changes were made. The images or other third party material in this article are included in the article's Creative Commons licence, unless indicated otherwise in a credit line to the material. If material is not included in the article's Creative Commons licence and your intended use is not permitted by statutory regulation or exceeds the permitted use, you will need to obtain permission directly from the copyright holder. To view a copy of this licence, visit http://creativecommons.org/licenses/by$\mathrm{nc} / 4.0 /$. 


\section{REFERENCES}

1. Ehteshami-Afshar S, Fitzgerald JM, Doyle-Waters MM, Sadatsafavi M. The global economic burden of asthma and chronic obstructive pulmonary disease. Int J Tuberc Lung Dis. 2016;20:11-23.

2. World Health Organization. Chronic obstructive pulmonary disease (COPD). Geneva, Switzerland: WHO, 2015. https://www.who.int/respiratory/ copd/en/ (2015).

3. GBD Chronic Respiratory Disease Collaborators. Prevalence and attributable health burden of chronic respiratory diseases, 1990-2017: a systematic analysis for the global burden of disease study 2017. Lancet Respir Med. 2020;8:585-96.

4. Brakema EA, Tabyshova A, Van Der Kleij RMJJ, Sooronbaev T, Lionis C, Anastasaki M, An PL, Nguyen LT, Kirenga B, Walusimbi S, Postma MJ, Chavannes NH, Van Boven JFM, Fresh Air Collaborators. The socioeconomic burden of chronic lung disease in low-resource settings across the globe - an observational fresh air study. Respir Res. 2019;20: 291.

5. Miravitlles M, Sliwinski P, Rhee CK, Costello RW, Carter V, Tan JHY, Lapperre TS, Alcazar B, Gouder C, Esquinas C, Garcia-Rivero JL, Kemppinen A, Tee A, Roman-Rodriguez M, Soler-Cataluna JJ, Price DB, Respiratory Effectiveness Group. Predictive value of control of COPD for risk of exacerbations: an international, prospective study. Respirology. 2020. https://doi.org/10.1111/resp.13811.

6. Price D, Fletcher M, Van Der Molen T. Asthma control and management in 8,000 European patients: the REcognise Asthma and LInk to Symptoms and Experience (REALISE) survey. NPJ Prim Care Respir Med. 2014;24:14009.

7. Bourbeau J, Bartlett SJ. Patient adherence in COPD. Thorax. 2008;63:831-8.

8. Makela MJ, Backer V, Hedegaard M, Larsson K. Adherence to inhaled therapies, health outcomes and costs in patients with asthma and COPD. Respir Med. 2013;107:1481-90.

9. Glerum PJ, Maliepaard M, De Valk V, Burger DM, Neef K. Drug switching in the Netherlands: a cohort study of 20 active substances. BMC Health Serv Res. 2020;20:650.

10. Bloom CI, Douglas I, Olney J, D'ancona G, Smeeth L, Quint JK. Cost saving of switching to equivalent inhalers and its effect on health outcomes. Thorax. 2019;74:1078-86.
11. Lavorini F, Levy ML, Dekhuijzen PN, Crompton GK, Admit Working Group. Inhaler choice and inhalation technique: key factors for asthma control. Prim Care Respir J. 2009;18:241-2.

12. Vrijens B, Dima AL, Van Ganse E, Van Boven JF, Eakin MN, Foster JM, De Bruin M, Chisholm A, Price D. What we mean when we talk about adherence in respiratory medicine. J Allergy Clin Immunol Pract. 2016;4:802-12.

13. Lavorini F, Usmani OS. Correct inhalation technique is critical in achieving good asthma control. Prim Care Respir J. 2013;22:385-6.

14. Boulet LP, Vervloet D, Magar Y, Foster JM. Adherence: the goal to control asthma. Clin Chest Med. 2012;33:405-17.

15. De Smet BD, Erickson SR, Kirking DM. Self-reported adherence in patients with asthma. Ann Pharmacother. 2006;40:414-20.

16. Van Boven JFM, Koponen M, Lalic S, George J, Bell JS, Hew M, Ilomaki J. Trajectory analyses of adherence patterns in a real-life moderate to severe asthma population. J Allergy Clin Immunol Pract. 2020;8:1961-9.

17. Bryant J, Mcdonald VM, Boyes A, Sanson-Fisher R, Paul C, Melville J. Improving medication adherence in chronic obstructive pulmonary disease: a systematic review. Respir Res. 2013;14:109.

18. Normansell R, Kew KM, Stovold E. Interventions to improve adherence to inhaled steroids for asthma. Cochrane Database Syst Rev. 2017;4:cd012226.

19. Wilson SR, Strub P, Buist AS, Knowles SB, Lavori PW, Lapidus J, Vollmer WM, Better Outcomes of Asthma Treatment (Boat) Study Group. Shared treatment decision making improves adherence and outcomes in poorly controlled asthma. Am J Respir Crit Care Med. 2010;181:566-77.

20. Sanchis J, Gich I, Pedersen S, Aerosol Drug Management Improvement Team (Admit). Systematic review of errors in inhaler use: has patient technique improved over time? Chest. 2016;150: 394-406.

21. Chrystyn H, Van Der Palen J, Sharma R, Barnes N, Delafont B, Mahajan A, Thomas M. Device errors in asthma and COPD: systematic literature review and meta-analysis. NPJ Prim Care Respir Med. 2017;27: $1-10$.

22. Kaplan A, Price D. Matching inhaler devices with patients: the role of the primary care physician. Can Respir J. 2018;2018:9473051. 
23. Price D, Chrystyn H, Kaplan A, Haughney J, Roman-Rodriguez M, Burden A, Chisholm A, Hillyer EV, Von Ziegenweidt J, Ali M, Van Der Molen T. Effectiveness of same versus mixed asthma inhaler devices: a retrospective observational study in primary care. Allergy Asthma Immunol Res. 2012;4:184-91.

24. Bosnic-Anticevich S, Chrystyn H, Costello RW, Dolovich MB, Fletcher MJ, Lavorini F, RodriguezRoisin R, Ryan D, Ming SWY, Price DB. The use of multiple respiratory inhalers requiring different inhalation techniques has an adverse effect on COPD outcomes. Int $\mathrm{J}$ Chronic Obstr Pulm Dis. 2016;12:59-71.

25. Van Der Palen J, Klein JJ, Van Herwaarden CL, Zielhuis GA, Seydel ER. Multiple inhalers confuse asthma patients. Eur Respir J. 1999;14:1034-7.

26. Pothirat C, Chaiwong W, Phetsuk N, Pisalthanapuna S, Chetsadaphan N, Choomuang W. Evaluating inhaler use technique in COPD patients. Int J Chronic Obstr Pulm Dis. 2015;10:1291-8.

27. Plaza V, Giner J, Rodrigo GJ, Dolovich MB, Sanchis J. Errors in the use of inhalers by health care professionals: a systematic review. J Allergy Clin Immunol Pract. 2018;6:987-95.

28. Ghosh S, Ohar JA, Drummond MB. Peak inspiratory flow rate in chronic obstructive pulmonary disease: implications for dry powder inhalers. J Aerosol Med Pulm Drug Deliv. 2017;30:381-7.

29. Loh CH, Peters SP, Lovings TM, Ohar JA. Suboptimal inspiratory flow rates are associated with chronic obstructive pulmonary disease and allcause readmissions. Ann Am Thorac Soc. 2017;14: 1305-11.

30. Sharma G, Mahler DA, Mayorga VM, Deering KL, Harshaw O, Ganapathy V. Prevalence of low peak inspiratory flow rate at discharge in patients hospitalized for COPD exacerbation. Chronic Obstr Pulm Dis. 2017;4:217-24.

31. Kaplan A, Hess M, Price D. Peak inspiratory flow (PIF) assessment tool: a simple tool for assessing the risk of suboptimal PIF (sPIF) in chronic obstructive pulmonary disease (COPD) [abstract American Academy of Family Physicians, AAFP, conference 2019].

32. Prime D, De Backer W, Hamilton M, Cahn A, Preece A, Kelleher D, Baines A, Moore A, Brealey N, Moynihan J. Effect of disease severity in asthma and chronic obstructive pulmonary disease on inhalerspecific inhalation profiles through the Ellipta(R) dry powder inhaler. J Aerosol Med Pulm Drug Deliv. 2015;28:486-97.
33. Mahler DA. Peak inspiratory flow rate as a criterion for dry powder inhaler use in chronic obstructive pulmonary disease. Ann Am Thorac Soc. 2017;14: 1103-7.

34. Mahler DA, Waterman LA, Gifford AH. Prevalence and COPD phenotype for a suboptimal peak inspiratory flow rate against the simulated resistance of the Diskus(R) dry powder inhaler. J Aerosol Med Pulm Drug Deliv. 2013;26:174-9.

35. Broeders ME, Molema J, Hop WC, Vermue NA, Folgering HT. The course of inhalation profiles during an exacerbation of obstructive lung disease. Respir Med. 2004;98:1173-9.

36. Kafaei Shirmanesh Y, Jones MD. Physical ability of people with rheumatoid arthritis and age-sex matched controls to use four commonly prescribed inhaler devices. Respir Med. 2018;135:12-4.

37. Iwata Y, Kakuta S, Osawa S, Fujimoto Y, Oki Y, Yamada Y. Relationship between cognitive function and proper inhaler device use in elderly patients. Eur Respir J. 2019;54:687.

38. Derendorf H, Nave R, Drollmann A, Cerasoli F, Wurst W. Relevance of pharmacokinetics and pharmacodynamics of inhaled corticosteroids to asthma. Eur Respir J. 2006;28:1042-50.

39. Postma DS, Dekhuijzen R, Van Der Molen T, Martin RJ, Van Aalderen W, Roche N, Guilbert TW, Israel E, Van Eickels D, Khalid JM, Herings RM, Overbeek JA, Miglio C, Thomas V, Hutton C, Hillyer EV, Price DB. Asthma-related outcomes in patients initiating extrafine ciclesonide or fine-particle inhaled corticosteroids. Allergy Asthma Immunol Res. 2017;9: 116-25.

40. Price D, Small I, Haughney J, Ryan D, GruffyddJones K, Lavorini F, Harris T, Burden A, Brockman J, King C, Papi A. Clinical and cost effectiveness of switching asthma patients from fluticasone-salmeterol to extra-fine particle beclometasone-formoterol: a retrospective matched observational study of real-world patients. Prim Care Respir J. 2013;22:439-48.

41. Leach C, Colice GL, Luskin A. Particle size of inhaled corticosteroids: does it matter? J Allergy Clin Immunol. 2009;124:s88-93.

42. Tervonen T, Hawken N, Hanania NA, Martinez FJ, Heidenreich S, Gilbert I. Maintenance inhaler therapy preferences of patients with asthma or chronic obstructive pulmonary disease: a discrete choice experiment. Thorax. 2020;75:735-43.

43. Doyle S, Lloyd A, Williams A, Chrystyn H, Moffat M, Thomas M, Price D. What happens to patients 
who have their asthma device switched without their consent? Prim Care Respir J. 2010;19:131-9.

44. Dahl R, Kaplan A. A systematic review of comparative studies of tiotropium Respimat(R) and tiotropium HandiHaler(R) in patients with chronic obstructive pulmonary disease: does inhaler choice matter? BMC Pulm Med. 2016;16:135.

45. Laba TL, Jan S, Zwar NA, Roughead E, Marks GB, Flynn AW, Goldman MD, Heaney A, Lembke KA, Reddel HK. Cost-related underuse of medicines for asthma-opportunities for improving adherence. J Allergy Clin Immunol Pract. 2019;7:2298-2306. e12.

46. Price D, Harrow B, Small M, Pike J, Higgins V. Establishing the relationship of inhaler satisfaction, treatment adherence, and patient outcomes: a prospective, real-world, cross-sectional survey of US adult asthma patients and physicians. World Allergy Organ J. 2015;8:1-11.

47. Rhee CK, Van Boven JFM, Yau Ming SW, Park HY, Kim DK, Park HS, Ling JZJ, Yoo KH, Price DB. Does changing inhaler device impact real-life asthma outcomes? Clinical and economic evaluation. J Allergy Clin Immunol Pract. 2019;7:934-42.

48. Park HS, Yoon D, Lee HY, Ban GY, Ming SWY, Jie JLZ, Carter V, Hardjojo A, Van Boven JFM, Price DB. Real-life effectiveness of inhaler device switch from dry powder inhalers to pressurized metred-dose inhalers in patients with asthma treated with ICS/ LABA. Respirology. 2019;24:972-9.

49. Price D, Chrystyn H, Kaplan A, Williams AE. ABS34: could interchangeable use of dry powder inhaler compromise quality of care? An international study of physicians and pharmacists. Prim Care Respir J. 2006;15:194.

50. Lavorini F, Braido F, Baiardini I, Blasi F, Canonica GW, SIAAC-SIMER. Asthma and COPD: interchangeable use of inhalers. A document of Italian Society of Allergy, Asthma and Clinical Immmunology (SIAAIC) \& Italian Society of Respiratory Medicine (SIMeR). Pulm Pharmacol Ther. 2015;34: 25-30.

51. Ha Dinh TT, Bonner A, Clark R, Ramsbotham J, Hines S. The effectiveness of the teach-back method on adherence and self-management in health education for people with chronic disease: a systematic review. JBI Database Syst Rev Implement Rep. 2016;14:210-47.

52. Van Boven JF, Ryan D, Eakin MN, Canonica GW, Barot A, Foster JM, Respiratory Effectiveness Group. Enhancing respiratory medication adherence: the role of health care professionals and cost-effectiveness considerations. J Allergy Clin Immunol Pract. 2016;4:835-46.

53. Global Initiative for Asthma (GINA). https:// ginasthma.org/ (2020). Accessed 5 July 2020.

54. Klijn SL, Hiligsmann M, Evers SMAA, Roman-Rodriguez M, Van Der Molen T, Van Boven JFM. Effectiveness and success factors of educational inhaler technique interventions in asthma \& COPD patients: a systematic review. NPJ Prim Care Respir Med. 2017;27:1-10.

55. Sanders MJ. Guiding inspiratory flow: development of the In-Check DIAL G16, a tool for improving inhaler technique. Pulm Med. 2017;2017:1495867. 